\title{
CHANGES IN PERIPHERAL BLOOD AND CYTOGENETIC INDICATORS DURING THE APPLICATION OF COMPOUNDS OF THE COPPER-ORGANIC COMPLEXES TO IRRADIATION
}

\begin{abstract}
Nikoghos Oganesyan, Carlo Santini, Anahit Karapetyan*, Ashot Dallakyan, Nektar Harutyunyan, Jasmina Petrosyan
\end{abstract}

Scientific Center of Radiation Medicine and Burns, Yerevan, Armenia

*Corresponding Author:ncrmio@web.am

KEYW ORDS — radiation, radioprotective compounds, proliferative activity, chromosomal aberrations, cell ploidy, red blood cell count, leukocyte count, hemoglobin level

\section{INTRODUCTION}

One of the priorities of the contemporary radiobiology is the search for new efficient radioprotective compounds. In this field metal-organic complexes of high antioxidant activity are of special interest. According to literature sources [1-4] and our early researches [5-9] such complexes have low toxicity and obvious radioprotective properties.

With a view to releave possible radiation protective actions, we studied compounds of copper-organic complexes: $\left[\mathrm{Cu}(\mathrm{PTA})_{4}\right] \mathrm{BF}_{4}$ and $\left[\mathrm{Cu}(\mathrm{PCN})\left(\mathrm{HBP}_{23}\right)\right]$ $\mathrm{BF}_{4}$, in which legands are: PTA-1,3,5-triaza-7-phosphaadamantane and PCN-tris(cyanoethyl)phosphine $\mathrm{HBP}_{23}$-trispyrazolilborato (hereinafter referred to as "PTA" and "PCN") which were synthesized in Camerino University (Italy) under the supervision of Professor Carlo Santini.

\section{MATERIALS AND METHODS}

The experiments were carried out on reproductive, white, outbred rats of both genders with middle-weight of 180-200 g. An hour before general, single-shot radiography of the animals with dose of $\mathrm{LD}_{50 / 30}-$ 5,3Gy and $\mathrm{LD}_{100 / 30}-7,0 \mathrm{~Gy}$, by PYM-17 equipment, PTA and PNC Cu-organic complexes were injected abdominally with dose of $20 \mathrm{mg} / \mathrm{kg}$ in the form of an aqueous suspension. Radioprotective activity of these compounds was estimated by survivability of average life expectancy which showed dynamics of experimental rats death during 30 days of monitoring.

Since ionizing radiation is essential disturbing factor of cytogenetic status of the organism, we analyzed radiation-induced clastogenesis of the bone marrow
Article history:

Submitted 20 November 2018

Accepted 14 April 2019

cells (BMC) as one of the most informative indicators. Generally accepted method of cytogenetic analysis of white rats' BMC indices was used. Proliferative activity (mitotic index-MI), chromosome aberration (CA), cell ploidy $(\mathrm{CP})$ was taken into consideration. We also performed hematological analysis of peripheral blood: red blood cell count, leucocyte count, level of hemoglobin.

Survival experiments were performed on 60 rats, 10 animals per group. Groups: net radiation with dose of 5,3Gy and 7,0 Gy (2 g) (control group); PTA+radiation with dose of 5,3Gy and 7,0Gy $(2 \mathrm{~g})$ and $\mathrm{PCN}+$ radiation with dose of 5,3Gy and 7,0Gy $(2 \mathrm{~g})$.

The results were also compared with the norm group - a group of non-irradiated animals and not receiving the tested complexes.

Statistical processing of digital material carried out using a number of computer programs. Microsoft Excel spreadsheet and specialized statistical packages Statsoft, SPSS, and StatGraphics Plus were used [10, 11].

\section{RESULTS}

Biomaterial was taken from 40 individual subjects: bone marrow was taken from femoral bone and periferic blood from tail vein. Indicators of survival and average life expectancy in the irradiated rats injected with the PTA and PCN complexes were higher than in animals from the control group (only irradiated) which revealed the radioprotective properties of the tested complexes (Table 1).

A survival analysis was also conducted using the regression method, which makes it possible not only to describe the dynamics of changes in indicators, but also the possibility of prediction. The logarithmic regression equations for survival were obtained for the control group (exposure to 5.3Gy-Y1) and groups of animals after the introduction of the PTA (Y2); PCN (Y3) of compounds (20 mg/ $\mathrm{kg}$ before irradiation) Y1 $=120.69-50.61 \lg (\mathrm{x}) ; \mathrm{Y} 2=107.62-20.01 \lg (\mathrm{x}) ; \mathrm{Y} 3=$ $110.9-21.5 \lg (\mathrm{x})$, where $\mathrm{x}$ is the number of days after irradiation at $5.3 \mathrm{~Gy}$.

Were also obtained regression curves and the corresponding equations describing the survival of groups 
Table 1. Survival and average life expectancy of rats

\begin{tabular}{|c|c|c|c|c|}
\hline \multirow{2}{*}{$\begin{array}{l}\text { Indicators } \\
\text { Groups }\end{array}$} & \multicolumn{2}{|c|}{ Survival (\%) } & \multicolumn{2}{|c|}{$\begin{array}{l}\text { Average life expectancy } \\
\text { in days }\end{array}$} \\
\hline & 5,3Gy & 7,0Gy & 5,3Gy & $7,0 \mathrm{~Gy}$ \\
\hline Control & 60 & 30 & 19,4 & 14,3 \\
\hline PTA+ irradiation & 80 & 60 & 26,8 & 25 \\
\hline $\mathrm{PCN}+$ irradiation & 80 & 60 & 27,3 & 25,9 \\
\hline
\end{tabular}

sion of proliferative activity in the control groups (net radiation with doses of 5,3 and 7,0Gy) is somehow descending (table 3). Comparison of proliferative activity of PTA and PTC groups with control groups showed that their significance is trustingly higher than that of the control groups.

A comparative analysis between the control groups and groups with experimental complexes showed that, regardless of radiation dose, significant decrease in the level of aberrant cells was observed. The
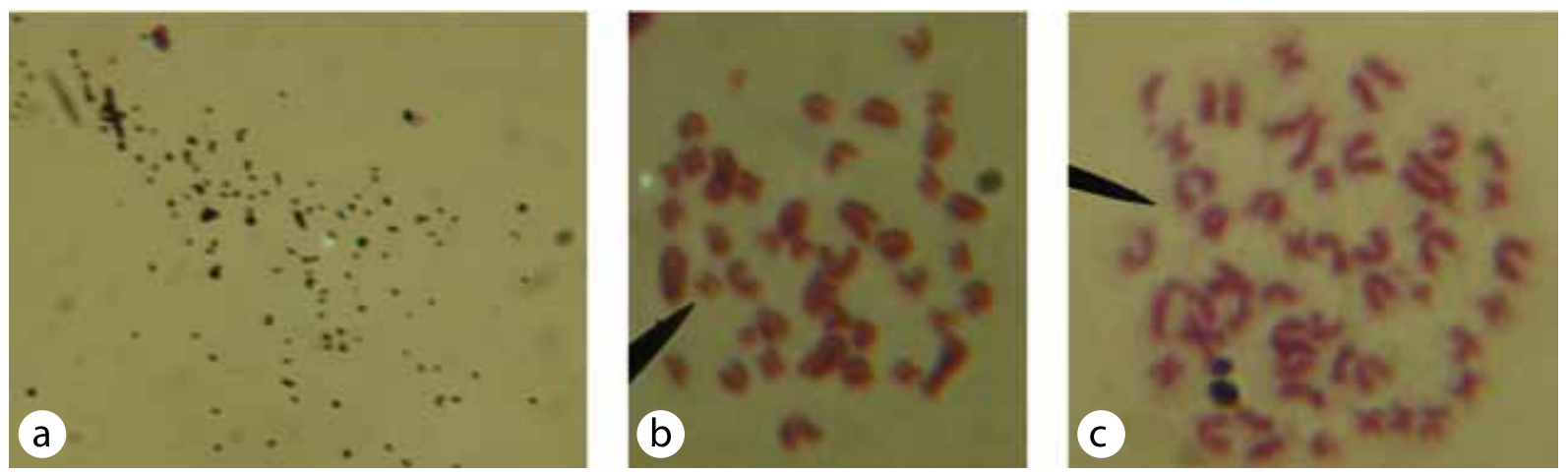

Fig. 1. Death of cells in the form of karyoclasis (a). Chromosome aberrations in the form of double fragment (b) and acentric circle (c).

of animals irradiated with a dose of $7.0 \mathrm{~Gy}(\mathrm{Y} 4$ is the control group), to which, prior to exposure, PTA (Y5) were introduced; $\mathrm{PCN}(\mathrm{Y} 6) ;: \mathrm{Y} 4=124.86-70.5 \lg (\mathrm{x})$; $\mathrm{Y} 5=113.4-30.6 \lg (\mathrm{x}) ; \mathrm{Y} 6=116.37-31.8 \lg (\mathrm{x})$, where $\mathrm{x}$ is the number of days after irradiation at 7.0 Gy.

Cytogenetic analysis were performed on the $3^{\text {rd }}$ and $30^{\text {th }}$ days post radiation exposure. The first period of analysis of the cytogenetic parameter showed that both radiation doses cause bone marrow syndrome: radiation block of mitoses and reproductive death of $\mathrm{BMC}$ leading to the devastation of the bone marrow (Fig. 1a). This syndrome is stronger expressed with the dose of 7,0Gy. However, statistically significant higher levels of proliferation is noted (Table 2) when comparing MI groups, which received $\mathrm{Cu}$-containing complexes, with control groups.

Analysis of the karyotype showed that chromosome aberrations in the form of fragments, acentric circles and translocations (Fig. 1 b, c) in all research groups with both doses of radiation significantly exceed the level of aberration of the intact group. When comparing CA group which received PTA and PCN with control groups, it should be noted that their aberration is significantly lower than the level of control values (Table 2).

Analisis of the cytogenetic indices on the 30th day of experiment showed that earlier noted depres- number of polyploids with an exposure dose of 5,3Gy in PTA and PCN groups is somehow below the control. With an exposure dose of 7,0Gy, this indicator is significantly lower in both groups with complexes compared with control ones.

Hematological indices were analysed in dynamics during the whole period of experiment. High radiation sensitivity of BMC which led to depression of hemapoiesis and death of formed elements just in blood vessels are the cause of severe erythro- and leukopenia and anemia. These three indicators in the early period $\left(3^{\text {rd }}\right.$ and $7^{\text {th }}$ days $)$ of a research were significantly below the sizes of the relevant standards. The exception makes hemoglobin level for the $7^{\text {th }}$ day at rats with the injected complexes with a dose of 5,3Gy.

As can be seen from table 4, on the last dates of observation (the $14^{\text {th }}$ and $30^{\text {th }}$ days) there was an increase in the number of erythrocytes and correspondingly there was an increase in the level of hemoglobin. When we compare the data standards in all groups, except control groups with dose of 5,3Gy on the 14th day and with dose of 7,0Gy on the 14th and 30th days, unreliable deviance from the standards is noted (Table 4).

Number of leukocytes on the $14^{\text {th }}$ day of analysis, despite the significant increase of its level in all groups, 
Table 2. Cytogenetic indices on the $3^{\text {rd }}$ day post radiation

\begin{tabular}{l|l|l|l|l|l|l}
\hline \multirow{2}{*}{ Indicators } & Groups & $3^{\text {rd }}$ day. Radiation with dose of 5,3Gy & \multicolumn{3}{l}{$3^{\text {rd }}$ day. Radiation with dose of 7,0Gy } \\
\cline { 2 - 8 } & Control & PTA+radiation & PCN+radiation & Control & PTA+radiation & PCN+radiation \\
\hline MI \% & $6,5 \pm 0,5$ & $8,8 \pm 0,72^{*}$ & $8,6 \pm 0,8^{*}$ & $4,2 \pm 0,4$ & $7,2 \pm 0,68^{*}$ & $6,9 \pm 0,6^{*}$ \\
\hline CA \% & $13,2 \pm 1,4$ & $7,6 \pm 0,7^{*}$ & $8,2 \pm 0,74^{*}$ & $17,5 \pm 1,5$ & $11,2 \pm 1,2^{*}$ & $12,8 \pm 1,3^{*}$ \\
\hline CP \% & $4,2 \pm 0,38$ & $3,8 \pm 0,4$ & $4,0 \pm 0,36$ & $6,4 \pm 0,6$ & $6,0 \pm 0,62$ & $5,9 \pm 0,47$ \\
\hline
\end{tabular}

Table 3. Cytogenetic indices on the $30^{\text {th }}$ day post exposure

\begin{tabular}{l|l|l|l|l|l|l}
\hline \multirow{2}{*}{ Indicators } & \multicolumn{3}{|l}{ Groups } & $30^{\text {th }}$ day. Radiation with dose of 5,3Gy & \multicolumn{3}{l}{$30^{\text {th }}$ day. Radiation with dose of 7,0Gy } \\
\cline { 2 - 8 } & Control & PTA+radiation & PCN+radiation & Control & PTA+radiation & PCN+radiation \\
\hline MI \% & $10,2 \pm 1,2$ & $16,8 \pm 1,48^{*}$ & $17,4 \pm 1,42^{*}$ & $8,4 \pm 0,74$ & $15,5 \pm 1,2^{*}$ & $16,3 \pm 1,4^{*}$ \\
\hline CA \% & $7,2 \pm 0,64$ & $4,8 \pm 0,5^{*}$ & $5,0 \pm 0,4^{*}$ & $12,2 \pm 1,2$ & $7,1 \pm 0,53^{*}$ & $6,9 \pm 0,5^{*}$ \\
\hline CP \% & $3,2 \pm 0,34$ & $2,8 \pm 0,22$ & $2,6 \pm 0,22$ & $4,6 \pm 0,38$ & $3,0 \pm 0,24^{*}$ & $3,2 \pm 0,27^{*}$ \\
\hline
\end{tabular}

Table 4. Dynamics of hematological indices post irradiation

\begin{tabular}{|c|c|c|c|c|c|c|c|c|}
\hline \multirow{2}{*}{ 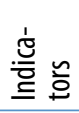 } & \multirow{2}{*}{ 흥 } & \multirow{2}{*}{ Groups } & \multicolumn{3}{|c|}{ Radiation with dose of 5,3Gy } & \multicolumn{3}{|c|}{ Radiation with dose of $7,0 \mathrm{~Gy}$} \\
\hline & & & Control & PTA+radiation & $\mathrm{PCN}+$ radiation & Control & PTA+radiation & PCN+radiation \\
\hline \multirow{4}{*}{ 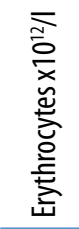 } & \multirow{4}{*}{$\begin{array}{l}\text { ñ } \\
\text { o } \\
+1 \\
\text { ஸे }\end{array}$} & 3 & $3,9 \pm 0,4$ * & $4,22 \pm 0,42 *$ & $4,16 \pm 0,38 *$ & $3,0 \pm 0,26^{*}$ & $3,4 \pm 0,32 *$ & $3,36 \pm 0,26 *$ \\
\hline & & 7 & $4,22 \pm 0,5$ * & $4,94 \pm 0,48 *$ & $4,88 \pm 0,4^{*}$ & $3,3 \pm 0,3 *$ & $4,0 \pm 0,38 *$ & $3,87 \pm 0,36$ * \\
\hline & & 14 & $5,0 \pm 0,52$ & $5,86 \pm 0,54$ & $5,69 \pm 0,52$ & $4,16 \pm 0,43 *$ & $4,8 \pm 0,5$ & $4,77 \pm 0,42$ \\
\hline & & 30 & $5,2 \pm 0,56$ & $6,0 \pm 0,56$ & $5,96 \pm 0,5$ & $4,4 \pm 0,5^{*}$ & $5,44 \pm 0,52$ & $5,42 \pm 0,54$ \\
\hline \multirow{4}{*}{ 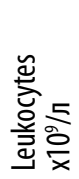 } & \multirow{4}{*}{ 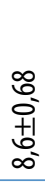 } & 3 & $0,45 \pm 0,05 *$ & $0,5 \pm 0,06^{*}$ & $0,52 \pm 0,05 *$ & $0,29 \pm 0,026^{*}$ & $0,32 \pm 0,04 *$ & $0,3 \pm 0,032 *$ \\
\hline & & 7 & $0,9 \pm 0,07 *$ & $1,24 \pm 0,22 *$ & $1,28 \pm 0,14 * * *$ & $0,5 \pm 0,04 *$ & $0,78 \pm 0,08 * * *$ & $0,76 \pm 0,06 * * *$ \\
\hline & & 14 & $2,2 \pm 0,3 *$ & $3,7 \pm 0,36 * * *$ & $3,58 \pm 0,33 * * *$ & $1,6 \pm 0,15 *$ & $2,85 \pm 0,26 * * *$ & $2,9 \pm 0,3 * * *$ \\
\hline & & 30 & $4,8 \pm 0,4^{*}$ & $6,2 \pm 0,54 * * *$ & $6,0 \pm 0,52 *$ & $3,5 \pm 0,34$ * & $5,2 \pm 0,5 * * *$ & $5,22 \pm 0,53 * * *$ \\
\hline \multirow{4}{*}{$\begin{array}{l}\overline{\text { б }} \\
\text { 흥 } \\
\text { 응 } \\
\text { 흫 } \\
\text { 포 }\end{array}$} & \multirow{4}{*}{\begin{tabular}{l}
0 \\
\multirow{J}{*}{} \\
+1 \\
$\infty$ \\
$\infty$
\end{tabular}} & 3 & $92,4 \pm 9,5^{*}$ & $110,0 \pm 11,2 *$ & $109,2 \pm 10,3 *$ & $81,3 \pm 7,4^{*}$ & $94,6 \pm 7,5^{*}$ & $93,8 \pm 8,2^{*}$ \\
\hline & & 7 & $100,0 \pm 9,8 *$ & $130,0 \pm 12,6$ & $129,4 \pm 12,2$ & $92,2 \pm 9,3 *$ & $106,0 \pm 9,7 *$ & $104,5 \pm 10,0$ * \\
\hline & & 14 & $115,6 \pm 12,0$ * & $142,0 \pm 14,3$ & $140,9 \pm 13,8$ & $106,4 \pm 10,2$ * & $128,5 \pm 11,5$ & $127,6 \pm 12,2$ \\
\hline & & 30 & $137,0 \pm 13,2$ & $150,4 \pm 14,6$ & $150,0 \pm 14,4$ & $118,0 \pm 11,5$ * & $142,5 \pm 13,7$ & $140,0 \pm 14,0$ \\
\hline
\end{tabular}

* — statistically significant deviance of indices from the norm

** _ statistically significant deviance of indices from the control

authentically remained below the standard level. When comparing the complex injected groups with control ones, statistically significant increase of this indicator was observed (Table 4). On the $30^{\text {th }}$ day this indicator in all groups still remains authentically below the standard (norm), but there is a persistent trend towards normalization.

\section{CONCLUSIONS}

Basing on the survival results, average life expectancy, cytogenetic and hematological indicators, it can be concluded that study complexes demonstrate noticeable radioprotective properties. Both complexes showed identical effects on experimental animals according to all observed criteria. 
In eruptive phase, on early dates of analysis ( $3^{\text {rd }}$ and $7^{\text {th }}$ days) both compounds soften the damaging effects of radiation with both doses which is especially obvious in significant shifts of mitotic index and CA in comparison with control data. On the last dates of observation ( $14^{\text {th }}$ and $30^{\text {th }}$ days) many data of analysis (MI, red blood readings) approached the standard data (norm), CA and number of leucocytes in comparison with the control data, demonstrate statistically significant difference.

Based on the results obtained, it can be assumed that the studied $\mathrm{Cu}$-ligands effectively promote reparative processes in bone marrow cells and have the properties of pronounced radiomodifiers.

\section{REFERENCES}

1. Bhirud R. G., Srivastava T. S. Superoxide dismutase activity of $\mathrm{Cu}(\mathrm{II}) 2$ (aspirinate) 4 and its adducts with nitrogen and oxygen donors. Inorganica Chimica Acta, 1990, V.173, (1), 121-125 DOI: 10.1016/S00201693(00)91063-6

2. SORENSON JOHN R.J., SODERBERG LEE S.F., Chang Louis W. Radiation Protection and Radiation Recovery with Essential Metalloelement Chelaties. Proc Soc Exp Biol Med., 1995 , 210:191-204, DOI: $10.3181 / 00379727-210-43939 a$

3. RILEY D.P. Functional mimics of superoxide dismutase enzymes as therapeutic agents, Chem. Rev. 1999 (99), 2573-2588. https://doi.org/10.1021/ cr990117+

4. Salvemini D., Riley D.P., Cuzzocrea S. SOD mimetics are coming of age. Nat. Rev. Drug Discover. 1. 2002, 367-374, DOI: 10.1038/nrd796

5. Malakyan M., Pogosyan A., Dallakyan A., Yegiazaryan D., Bajinyan S. Radioprotective properties and cytogenetic activity of $\mathrm{Cu}(\mathrm{II})(\mathrm{Ni}$ continyl-L- Tyrosinate) 2 in X-ray irradiated rats. $38^{\text {th }}$ Ann. Meeting of European Research Society Abstracts, Stockholm, 5-9 September, 2010, p. 141

6. Malakyan M., Bajinyan S., Martirosyan V., Tonoyan V., Babayan K., Tadevosyan D., Yegiazaryan D., Pogosyan A., Dallakyan A. ET ALL, Synthesis and radioprotective properties of copper complexes of Schiff basses derived from L-histidine and pyridinecarboxaldehyde. International Conference Radiation Safety challenges in the $20^{\text {th }}$ Certury Proceedings, Yerevan, 2012, p. 57-60

7. Malakyan M., Dallakyan A., Bajinyan S., Tonoyan V., Ayvazyan V., Karapetyan N. Development of Potential Radioprotective Agents For USE in Field Exposure Situations. "BRIte" Biomarkers of Radiation in the Environment: Robust tools for risk assessment", Yerevan, Armenia, 2017, p. 22

8. Poghosyan A.S., Dallakyan A.M. Cytogenetic Consequence of radiation "Ageing" of organism. NIRS-IAEA Workshop on Cytogenetic Biodosimetry for Asia incorporation with WHO 2011, p. 420
9. Pogosyan A.S., Dallakyan A.M., Karapetyan A.G., HovhanNesYan A.N. Role and probable mechanisms of polyploidy cells formation in irradiated organism. International Conference Radiation Safety challenges in the $21^{\text {th }}$ Century. Proceedings, Yerevan, 2012, p. 85-86

10. VuKolov E.A. Fundamentals of statistical analysis. Workshop on statistical methods and investigation of operations using STATISTICA and EXCEL packages, Moscow, Forum. 2008, - 464 p. (rus)

11. Bureeva N.N. Multidimensional statistical analysis with use of a package of applied programs STATISTICA, Bottom Novgorod: NNGU, 2007, - 112 p. (rus) 